\title{
El primer virreinato americano
}

\author{
Roberto Cassá y Raimundo González de Peña \\ Archivo General de la Nación \\ Genaro Rodríguez Morel \\ Academia Dominicana de la Historia
}

El artículo trata sobre el gobierno de Cristóbal Colón en tierras americanas. Retomamos el tema del primer emplazamiento español en Santo Domingo y las contradicciones que tuvo aquel proyecto debido a la lógica del estado absolutista, a la ambición desmedida del descubridor y a su reacción ante los controles que desde un principio impusieron los monarcas. En un segundo momento analizamos las dificultades que encontró el Almirante para desarrollar un modelo mercantilista acorde a sus ideas y a los acuerdos a que llegó con la Corona. En ese contexto analizamos la lógica del primer gobierno colombinista en las Indias y los rasgos que definieron la nueva sociedad antillana.

Palabras Clave: Cristóbal Colón, Santo Domingo, Virreinato.

This article explores the government of viceroy Christopher Columbus in the American territories. We return to the first Spanish settlement in Santo Domingo and the contradictions inherent to this expansionist proyect. The contradictions were part of the logic of the absolutist state and Columbus' reaction against the controls imposed by the monarchs. Secondly, we look into the dificulties that the Admiral encountered to develop a mercantilist model. In this context, we examine the rationale behind the first government of the Indies and the features that defined the new West Indian society.

KeYwoRDS: Christopher Columbus, Santo Domingo, Viceroyalty.

El presente trabajo está orientado a retomar el debatido tema del primer emplazamiento español en América, establecido en la isla de Santo Domingo (Haití o La Española) a finales de 1493. Como es bien sabido, los contornos del proyecto de expansión de la monarquía castellana se perfilaron inicialmente de manera exclusiva dentro de los marcos de la sociedad mercantil establecida entre la corona española y Cristóbal Colón y de las atribuciones acordadas por la primera a este último. Colón se encontraba de tal manera en una doble condición de sujeto privado y funcionario investido de prerrogativas inherentes a la autoridad española en las nuevas tierras. 
Esta posición de Colón dio lugar a una situación sui generis característica de la etapa en que la presencia española estuvo vinculada a su persona. Recibió atribuciones de autoridad prácticamente omnímodas y una participación exclusiva dentro de los beneficios económicos del proyecto. Este tipo de posición, si bien todavía se estilaba entre figuras prominentes del aparato de la monarquía absoluta, provenía de la atribución de dignidades gubernamentales a nobles que conmutaban derechos. Reconocido como "grande", en la cúspide de la nobleza de Castilla, Colón quedó investido, en forma vitalicia y hereditaria, de la condición de virrey y almirante. De la misma manera, se le otorgaba la potestad para conocer los casos de apelación en el sistema judicial. En el aspecto económico, recibiría una décima parte de los beneficios en metales y piedras preciosas y especies, y hasta un octavo de los beneficios comerciales, siempre y cuando aportara los recursos correspondientes para la empresa. ${ }^{1}$

Estos puntos ponen en evidencia que existía un doble propósito en la empresa proyectada entre los reyes y Colón: el mercantil y el territorial. El fortalecimiento de la monarquía absoluta retroalimentó los requerimientos para una expansión ultramarina de la cual se derivasen ingresos extraordinarios, especialmente en metales preciosos y otros artículos que arrojasen valores elevados. Desde su fase de definición, estaba claro que la empresa traspasaba los marcos de la experiencia portuguesa en África, limitada a fortificaciones concebidas para entablar relaciones comerciales con las formaciones sociales cercanas. El acuerdo entre las dos partes presuponía implícitamente la posibilidad de la expansión militar, por lo que empezó a plasmarse con la fundación del fuerte de La Navidad.

Más allá, sin embargo, era casi nada lo que estaba predefinido. La empresa colonizadora, como cualquier otra, estaría sujeta a especificaciones y concreciones, pero en mayor grado que en un entorno común, puesto que tenía como referencia un espacio brumoso, lo que se conocía, entre confusiones y errores, como Asia oriental. En la práctica, el contacto con un panorama desconocido conllevaría redefiniciones obligadas en el corto plazo.

Lo más importante dentro de este ámbito de indefinición fue que la sociedad mercantil excluía a los españoles, como entes privados, de la par-

1 Véanse las Capitulaciones entre los Reyes Católicos y Cristóbal Colón, Santa Fe de la Vega de Granada, 17 de abril de 1492. Archivo General de Indias (en adelante, A.G.I.), 295, 2. Los títulos fueron confirmados a Colón por real provisión de 30 de abril del mismo año. Véase Fernández de Navarrete, M.: Obras, tomo I, Edición y estudio preliminar de Carlos Seco Serrano, B.A.E., Ediciones Atlas, Madrid,1954, Doc. VI, págs. 304-305. 
ticipación en los beneficios. La explotación de los recursos de las nuevas tierras debería quedar reservada en lo fundamental a la sociedad mercantil.

Con un primer conocimiento del espacio antillano, a finales de 1492, el escenario inesperado, magnificado por la distancia y la precariedad de las comunicaciones, iría a redundar en beneficio de la ratificación de la autoridad omnímoda de Colón. Los amplios márgenes de autoridad que se le ratificaron en los primeros meses de 1493 significaban que los monarcas españoles captaron que el futuro de la empresa seguía sujeto a la capacidad excepcional de Colón.

Tal interés compartido no fue óbice para que, desde sus orígenes, la empresa en realidad albergara dos proyectos, en retroalimentación obligada y creciente tensión. La monarquía apuntaba, aunque confusamente en sus inicios, a instaurar un orden similar al que había ya logrado en la Península dentro del absolutismo. Colón, por su parte, se limitaba a tratar de detentar la mayor concentración posible de prerrogativas vinculadas a su persona. El beneficio de una de las partes se hacía necesariamente a costa del perjuicio de la otra. A la larga, a pesar de las coincidencias iniciales de obtención de beneficios compartidos y de la extensión de la soberanía castellana a las tierras "descubiertas", se desprendían dos esquemas de sociedad. El virreinato de Colón iría tomando forma en una rápida evolución determinada por el juego de los intereses involucrados.

La situación excepcional, impuesta por Colón como condición para integrarse en la empresa, tuvo que ser aceptada por los monarcas a pesar de que contravenía el designio absolutista. Así consta, además de en las capitulaciones -ratificadas con el privilegio de sello rodado en mayo de 1493-, en las instrucciones del segundo y tercer viajes, además de en múltiples cédulas en las que se recalca la autoridad del Almirante. Por ejemplo, después de las primeras quejas sobre el gobierno del Almirante, los reyes señalan que don Cristóbal Colón "es nuestro virrey e gobernador (...) por virtud de nuestras cartas de poderes que para ello le mandamos dar e dimos", ordenando que se le obedeciera en todo "como si nos en persona vos lo mandásemos, so las penas que vos pusiere e mandare poner de nuestra parte, las cuales por la presente vos ponemos e habemos por puestas; e para las ejecutar en los que lo contrario hicieren, damos poder cumplido al dicho almirante don Cristóbal Colón o a quien su poder hubiere."”

2 Real Provisión dada en Segovia, 16 de agosto de 1494. A.G.I., 295, 25,1. 
Hasta cierto punto, a Colón se le dejó carta abierta, aunque en ocasiones su autoridad quedó indefinida, sujeta a resoluciones ulteriores, e incluso a cuestionamientos velados. Los monarcas procuraron en todo momento restringir los alcances de la autoridad del molesto socio y funcionario, con el fin de prevenir cualquier tentación feudal, sin embargo, los controles del aparato estatal metropolitano no podían operar, lo que contribuyó a que Colón pudiera perpetuar su control. El virrey-almirante pudo detentar un margen crucial para definir los contenidos y los procedimientos de la empresa y el ordenamiento global de la expansión castellana. Tal potestad le permitió operar en el sentido exclusivista de privilegiar su interés personal en detrimento de un diseño global, afín a la perspectiva monárquica. ${ }^{3}$

Pero el proyecto de Colón pronto se encontró con escollos fundamentales. Se puso de relieve con rapidez que el diseño administrativo y económico no encajaba con los marcos de la sociedad autóctona encontrada. La naturaleza de la autoridad de Colón dio lugar a una doble dificultad. El margen de discrecionalidad que se arrogó permitió que pudiera mantener el gobierno con un mínimo de funcionalidad, pese a los diversos órdenes de oposición que fueron presentándose.

En relación a estas atribuciones y a los contornos generales de la empresa ultramarina, se pueden distinguir dos etapas básicas de aquel primer virreinato americano: la correspondiente a los años que van desde 1493 hasta 1498, posterior al segundo viaje; ${ }^{4}$ y la segunda, entre 1498 y 1500 , entre el tercer viaje y su caída. En la primera, se mantuvo la exclusión de la población española de los beneficios de la empresa. En la segunda etapa, Colón fue forzado a realizar concesiones que implicaban una disminución de la restricción monopólica de la sociedad mercantil. La rebelión del alcalde mayor Francisco Roldán, a finales de 1496, marcó el punto de inflexión de los conflictos generados por el monopolio mercantil y terminó de crear las condiciones para el paso a la segunda etapa.

3 Giménez Fernández caracterizó la empresa capitulada entre Colón y los reyes como "pura y simplemente económica"; y al referirse a la supresión del Virreinato capitulado con Colón (14921500) por parte de los reyes, subrayó la diferencia abismal de poder que ostentó don Cristóbal con respecto a su hijo don Diego, quien gozó del título más tarde. Véase Giménez Fernández, M.: Bartolomé de las Casas I. Delegado de Cisneros para la reformación de las Indias, 1. reimpresión, Consejo Superior de Investigaciones Científicas, Escuela de Estudios Hispanoamericanos, Sevilla, 1984, págs. 24-27.

4 Dentro de ese primer período se reveló la "crisis del prestigio colombino", como la llama Juan Gil, pero todavía persiste el proyecto monopolista como empresa dual. Véase Gil, J.: Mitos y utopías del descubrimiento, vol. 1, Alianza Editorial, Madrid, 1985. 
Tal deslinde de situaciones en realidad sólo cubrió aspectos del proyecto, y se hizo evidente la falla crucial del designio de Colón acerca de los mecanismos de sostenimiento material de la sociedad comercial. Por una parte, se puso de manifiesto una flagrante imposibilidad de éxito del diseño socioeconómico, hecho que junto a la autoridad omnímoda generó conflictos que forzaron redefiniciones fundamentales y a la larga crearon las condiciones que dieron lugar a la bancarrota del virrey-almirante.

Colón y los monarcas convinieron en un pacto genérico depredador de las poblaciones que se encontrasen en los viajes de descubrimiento y en las transacciones comerciales. Correspondió a Colón definir los rasgos de plasmación del esquema de sociedad. Su componente básico radicó en el establecimiento de una relación tributaria con la población aborigen. La Corona mostró su aquiescencia en tanto que permitía conferir condición de súbditos a los aborígenes, lo que a su vez quedaba justificado con la misión de su evangelización. De las modalidades de explotación de los indios adaptadas al propósito monopolista de la sociedad mercantil se derivó el conjunto de relaciones institucionales y sociales. De este modo el sistema virreinal resolvió el estatus y la función de la población española. Colón concebiría, siempre de acuerdo con los reyes, un mecanismo integrado de interdependencia entre el procedimiento tributario de explotación de la mano de obra indígena y la posición particular de la población española.

Lo más destacable al respecto radicó en la separación tajante entre las comunidades de indios y españoles. Los españoles tendrían que estar al servicio, directa o indirectamente, del monopolio de la sociedad mercantil a cuya cabeza se encontraba el almirante. La subordinación de la población aborigen, como medio para compelerla a abonar el tributo, tenía por contrapartida la imposibilidad de su explotación privada por parte de los residentes españoles, a menos en lo concerniente a la extracción de metales, piedras preciosas y bienes equivalentes. La comunidad española en realidad no quedaba en posición dominante sobre la indígena, sino accesoria del mecanismo central de explotación.

Está bien establecido que el fracaso del sistema tributario provino de una realidad insuperable: el bajo nivel de desarrollo de la tecnología aborigen para la extracción de oro. En cualquier otro ámbito el nivel de las fuerzas productivas de los taínos y las otras etnias no se correspondía con los requerimientos de una extracción significativa y continua de excedentes. Las ansias desmesuradas de riquezas que animaba a las dos partes envueltas en la sociedad mercantil exacerbaron esta contradicción y contribuye- 
ron a preparar las condiciones de la posterior bancarrota. Por otro lado, la marginación del interés privado de los pobladores españoles hizo detonar en el plano social la inviabilidad del esquema tributario, por los perjuicios inmediatos que se desprendieron del régimen laboral. En su mayoría, los españoles se encontraban a sueldo de la sociedad comercial, por lo que no podían relacionarse privadamente con los aborígenes, con la secuela de la obligatoriedad de realizar labores manuales y atravesar condiciones precarias de vida. Esto no se correspondía con el propósito aventurero que los había traído a las nuevas tierras. Su oposición al monopolio mercantil se puso de manifiesto casi desde el momento en que se fundó la ciudad La Isabela y, a la larga, minaría de manera decisiva la posibilidad de persistencia del virreinato.

Durante la primera etapa, Colón desarrolló sucesivos procedimientos de explotación de la población aborigen. Primeramente operó por medio de "rescates" de oro a cambio de artículos europeos de muy bajo valor, mecanismo que se inició en el islote Guananí. Los resultados de este procedimiento fueron del todo decepcionantes.

En segundo lugar, se iniciaron acercamientos a las tribus aborígenes sobre la base de una institución de éstas: el guaitiao. Se trataba de una relación de alianza amistosa entre dos principales, con un componente de compenetración de identidades basado en el intercambio de nombres. Guacanagarix fue el primer cacique que se hizo guaitiao de un europeo, el mismo Colón. Con esta modalidad de alianza Colón pretendía, además de penetrar en las sociedades aborígenes y obtener dividendos de ellas, enfrentarlas con otras como parte de un designio más sistemático de dominio.

Cuando el panorama geográfico y demográfico insular estuvo suficientemente claro, Colón se propuso obtener la aceptación voluntaria de vasallaje de las tribus hacia la autoridad de la monarquía castellana. Si los aborígenes no aceptaban esta subordinación de manera voluntaria, se recurriría a la compulsión violenta mediante la conquista.

Estos dispositivos fueron puestos en práctica, algunos momentáneamente y otros de manera simultánea. Se logró con ellos someter a la generalidad de las tribus de las tres etnias a la autoridad efectiva del virreinato. Prácticamente ninguna comunidad importante quedó liberada de las compulsiones que se derivaban de la aceptación de la soberanía de los reyes

5 Véase Szászdi Guatiao, I.: "Los primeros tratados de Indias", Actas del IX Congreso del Instituto Internacional de Historia del Derecho Indiano, tomo I, Madrid, 1991. 
españoles. La culminación de este proceso en la isla acaeció durante la administración provisional de Bartolomé Colón, en ausencia de su hermano, entre 1496 y 1498, cuando los postreros remisos a la aceptación del dominio español terminaron aplastados. Los últimos fueron los ciguayos, habitantes de la porción nordeste de la isla, los de mayor capacidad bélica por su origen caribe.

Aun así, el monto de los excedentes recibidos por la sociedad comercial no traspasaba un nivel insignificante. La empresa carecía de los medios para obligar a los aborígenes a adaptarse a sus requerimientos materiales, de acuerdo con el esquema de separación de las "repúblicas" de indios y españoles que ordenaba la relación tributaria. Colón acudió entonces a un último expediente, la esclavización de indígenas reputados de rebeldes bajo supuestos variados, como la "justa guerra" o atribuidas manifestaciones de "contranatura".

Con la esclavización se buscaba primordialmente compensar la falta de rentabilidad de la empresa, abriendo un flujo de cautivos para ser vendidos en la península y eventualmente en otros puntos del Mediterráneo. ${ }^{6}$ Además, Colón intentó pagar con esclavos los salarios atrasados de los españoles, con el fin de satisfacer sus ansias de dignidad social, no molestar la atención de los monarcas y evitar que se pusiese de manifiesto la ineficiencia de todo el aparato administrativo. Aunque con dudas, los monarcas autorizaron la esclavización y el tráfico de taínos hacia Europa, acogiendo el argumento de la "justa guerra" como uno de los dispositivos para racionalizar el proyecto ultramarino.?

La imposición de la soberanía castellana sobre las comunidades aborígenes fue concebida por medio de una cadena de fortalezas. A partir de La Isabela, situada en la costa septentrional, se planteó un doble propósito, que resumía la visión formada por Colón para dar sustancia al virreinato. Por una parte, la ciudad debía servir de base para expediciones de navegación hacia los territorios cercanos, con vistas a terminar de establecer las rutas de navegación con Europa. El segundo propósito consistía en ser útil para penetrar los territorios interiores y sojuzgar sus poblaciones. La relación con la población aborigen estaría condicionada por su mayor o menor colombino",

6 Véase Gil, J.: Mitos y utopías del descubrimiento, vol.1, cap. "Crisis del prestigio

7 Sobre estas dudas, véase el estudio de Rodríguez Valencia, Vicente: "Isabel la Católica y la libertad de los indios de América. Devolución de los esclavos", Anthologica Annua, (Roma), números 24-25, 1971, págs. 645-680. 
cercanía a los yacimientos auríferos. De ahí que el primer emplazamiento interior fuese la fortaleza Santo Tomé, ubicada en Jánico, en los montes Cibao, donde se suponía que existía la mayor cantidad de oro. De la misma manera, las siguientes fortalezas se concibieron para rodear por el norte a Cibao, asegurar la pacificación de la población y el flujo de los recursos esperados. ${ }^{8}$

Hubo dos momentos principales en el designio de sujeción de los aborígenes. El primero tuvo que ver con la derrota de la confederación de tribus comandada por Caonabo, cacique de Maguana, al sur de los montes Cibao. Colón diseñó una estratagema para capturar al cacique, que finalmente fue confiada a Alonso de Ojeda. ${ }^{9}$ La captura del jefe tribal indudablemente redujo los riesgos de una sublevación generalizada o de una situación que estorbase la explotación económica. De todas maneras, durante meses los españoles debieron ocuparse de vencer la resistencia que siguieron presentando los hermanos y algunos de los caciques subordinados de Canoabo. ${ }^{10}$

El segundo momento, todavía más difícil, se presentó cuando Colón retornó de su viaje de exploración por Jamaica y Cuba, en diciembre de 1494. La población española se encontraba en situación crítica por la imposibilidad de procurarse alimentos de las comunidades aborígenes. La concepción de Colón de racionalizar los alimentos traídos desde España se reveló inoperante. ${ }^{11}$ Las presiones exacerbaron las ansias de rebelión entre los taínos. Finalmente, los caciques agrupados en la confederación de Maguá, encabezados por Guarionex, se propusieron forzar la retirada de los españoles. En los meses previos se había registrado una escalada de resistencias y castigos, saldada en esclavizaciones y un estado generalizado de

8 Sobre el número de fortalezas fundadas por el almirante podemos ver a Bartolomé de Las Casas: Historia General de las Indias, 3 vols., Edición de Agustín Millares Carlo y estudio preliminar de Lewis Hanke, Fondo de Cultura Económica, México, 1951.

9 Dicha operación había sido originalmente asignada a Mosén Pedro Margarite, quien habría desistido de su cumplimiento por considerarla impropia de un noble. Véase Ramos Pérez, D.: El conflicto de las lanzas jinetas. El primer alzamiento en tierra americana, durante el segundo viaje colombino, Casa-Museo de Colón / Seminario Americanista de la Universidad de Valladolid, 1982, págs. 94-96.

10 Véase Varela, Consuelo: La caída de Cristóbal Colón. El juicio de Bobadilla, Edición y trascripción de Isabel Aguirre, Marcial Pons, Madrid, 2006.

11 En efecto, se le había ordenado al virrey-almirante en 1495 , por diversas cédulas e instrucción que llevó Juan de Aguado, que no quitase por ningún motivo los alimentos a los colonos, aun en el caso de que estuviesen castigados. La real cédula dada en Arévalo a primero de junio de 1495, ordenaba que "de aquí adelante hagáis repartir los dichos mantenimientos al respecto y por la tasa que (...) debe haber cada persona”. A.G.I., 9, 1, 91v. 
confrontación. El momento presentaba mayor delicadeza debido a que el control de esta zona resultaba imprescindible para acceder al oro. Paulatinamente los españoles fueron abandonando La Isabela, tanto para obtener recursos alimenticios como para aproximarse a las fuentes del oro. La fortaleza de La Concepción se tornaría en la piedra angular de todo el dispositivo, hasta tal punto que, después de su retorno a la isla en 1498, Colón la hizo el centro de sus actividades.

En la zona de influencia de Maguá existía una numerosa población sobre la que pasó a recaer el grueso de las demandas del tributo. La derrota de Guarionex y las decenas de caciques dependientes, en los primeros meses de 1495, saldó el momento álgido de control sobre la isla. Quedaron los extremos por ocupar, pero para Colón no revistió mayor problema, puesto que no había noticias acerca de que en ellos se encontrasen grandes yacimientos. Guacanagarix, uno de los caciques importantes (los "mantunharí de las tribus aldeanas, reconocidos como "reyes" por los cronistas españoles) de los extremos, colaboró en el sometimiento de los caciques rivales, Canoabo y Guarionex. Bohechío, el cacique de Xaragua, el de mayor poder de la isla, al poco tiempo aceptó sin mayor dificultad abonar el tributo en algodón.

En el centro de la isla se puso a prueba la viabilidad del esquema tributario tras la derrota de las tribus de Maguá. Colón pretendió el cobro de la astronómica cantidad de un cascabel de oro per capita cada tres meses. El sistema resultó un fracaso flagrante ante el cual Colón persiguió nuevas estrategias, sin que lograra contener los conflictos que escenificaban indios y españoles. Las presiones a las que fueron sometidos los taínos del valle de la Vega Real dieron como resultado un estado crónico de confrontación, manifestado en compulsiones terroristas, sucesivas sublevaciones y en otras salidas en respuesta, como suicidios colectivos y escapadas a los bosques.

Mientras la resistencia aborigen exacerbaba la imposibilidad objetiva de viabilidad del sistema tributario y del conjunto de la sociedad mercantil, fue con el agravamiento del cuestionamiento de los españoles cuando se abrieron redefiniciones y se preparó su final con la destitución de Colón.

Para muchos la empresa se había saldado en un fiasco, por lo que se propusieron retornar de inmediato a España, a lo que Colón se opuso haciendo uso de sus prerrogativas autocráticas. Las disensiones alcanzaron a algunas de las personas que habían sido comisionadas por los monarcas como garantes de sus intereses pero cuya capacidad de incidencia en la 
dirección de los asuntos se había mostrado nula frente a la autoridad del virrey. Hasta Bernardo Buil, jefe de la misión sacerdotal, a quien Colón había designado en un consejo ejecutivo en su ausencia junto a su hermano Diego, optó por retornar a España en compañía de Pedro Margarite, un noble aragonés que había estado al frente de la fortaleza de Santo Tomé. ${ }^{12}$

Ante esta situación, los monarcas enviaron al visitador Juan de Aguado, a fin de que se informara de lo que acontecía. Al ver su autoridad puesta en juicio, el almirante consideró inevitable ir a la corte y pedir explicaciones. Es sintomático que, a pesar del malestar generado por el esquema tributario de la sociedad mercantil entre casi todos los residentes españoles, los reyes todavía considerasen conveniente ratificar la autoridad de Colón durante su estadía en la Península entre 1496 y 1498.

Con el fin de acallar las voces que se pronunciaban en su contra, el almirante atisbó una solución básica de los conflictos de acuerdo con sus intereses mediante el desplazamiento del eje del control del territorio en dirección sur. Inmediatamente antes de su viaje a España habían llegado informaciones acerca de la existencia de ricos yacimientos auríferos en el río Haina, cuyas cabeceras no distaban de Bonao, donde se había construido la última fortaleza de la cadena. Además de la construcción de un nuevo fuerte, San Cristóbal, en su condición de Adelantado, Bartolomé Colón procedió con posterioridad a fundar una ciudad en la costa meridional que debía tomar el relevo de la moribunda La Isabela.

La proyectada marcha hacia el sur no conjuró sin embargo los conflictos dentro del virreinato. Fue precisamente en ausencia de Colón cuando se produjo la rebelión encabezada por Francisco Roldán, alcalde mayor de La Isabela, en demanda del derecho al retorno inmediato pero en cuestionamiento global de la sociedad mercantil, de la autoridad del virrey y del esquema tributario. Una tercera parte de los españoles se sumaron a los rebeldes, con lo que se creó un ambiente de guerra civil. Empero, los roldanistas se refugiaron en Xaragua, donde se integraron en las tribus en condiciones ventajosas. Si bien ya estaba trillado el camino de refugio de españoles en las aldeas indígenas, los roldanistas instauraron el precedente alternativo al sistema tributario y a la modalidad del mando de Colón.

Antes del retorno a la corte de Colón en 1496, los monarcas ya tenían una visión acerca de los problemas ocasionados por el esquema tributario y que se focalizaba en la recusación generalizada de la persona de

12 Varela, C.: La caída... pág. 25. 
Colón. Una escalada de cuestionamientos y castigos rarificó en extremo el ambiente. En el citado libro de Consuelo Varela, en el que se edita un interrogatorio acerca del gobierno de Colón con motivo de la llegada de su sustituto, Francisco de Bobadilla, se aporta información de gran interés acerca de los procedimientos odiosos con que Colón intentó mantener la estabilidad y la obediencia de los españoles.

Con todo y juzgando por lo visto la conveniencia de seguir confiando en Colón la tarea de expandir los alcances territoriales de la empresa, los monarcas lo ratificaron. Sin embargo, tal ratificación se llevó a cabo sobre la base de modificaciones que requirieron largas negociaciones. Todavía sin conocimiento de la rebelión de Roldán, los monarcas demandaron cambios que iban en perjuicio de los intereses de Colón. Se hacía patente el requerimiento de implantar instituciones propias del absolutismo que disminuyesen las prerrogativas principescas del virrey-almirante y abrieran la opción de la colonización. En otras palabras, todavía sin desechar la vigencia de la sociedad comercial y de los poderes de Colón, se planteó la coexistencia de una corriente de colonización sustentada en el reconocimiento del interés privado de residentes españoles.

Evidentemente esto no fue del agrado del almirante, pues no tenía un buen criterio de los españoles que estaban en la isla, sobre todo de aquellos que no aceptaban la manera en que ejercía el poder. A su desprecio no escapaban ni los religiosos; a los castellanos que vivían en la isla los describió como "gentes perdidas que sólo habían ido a enriquecerse sin trabajo ni pena, jugadores de dados y perezosos y de malas costumbres cegados por la codicia". ${ }^{13}$

La novedad crucial de estos acuerdos residió en la disposición de conceder tierra en plena propiedad a los españoles que demostrasen pasar cierto tiempo en la isla dedicados a actividades productivas. Es decir, una porción de los pobladores españoles quedaba desligada formalmente de los alcances de la sociedad mercantil, con lo que uno de sus pilares, el monopolio, quedaba abrogado. Se abría así una segunda fase de la existencia de aquel singular virreinato. Pero todavía se excluía del interés privado todo aquello sobre lo cual la Corona pretendía apropiarse de manera exclusiva, particularmente el oro. Esta apertura pareció responder en un primer momento a la necesidad de disminuir los costos de la empresa, dado que

13 Varela, C. y Gil, J.: Cristóbal Colón. Textos y documentos completos. Nuevas cartas, Alianza Editorial, Madrid, 1992, pág. 314. 
los prometidos resultados se hacían esperar. Con vistas al tercer viaje, en 1497, los reyes limitaron el número de personas a sueldo a quinientos, por lo que consideran que deben regresar todos aquellos que sobrepasen esa cantidad. ${ }^{14}$

Tras su retorno a la isla en el tercer viaje, en agosto de 1498, tras topar costas del continente, Colón se encontró con un panorama complejo, que requirió de concesiones suplementarias, en principio en detrimento de su autoridad sobre los españoles y, sobre todo, de la variante tributaria de la explotación de los indios. Los roldanistas alzados en Xaragua habían implantado una sociedad alternativa, consistente en la relación con las aldeas indígenas y en su aprovechamiento privado sobre la base de las instituciones aborígenes. Esos rebeldes afirmaban acatar únicamente la autoridad del rey como medio de desconocer a Colón. Demandaban el derecho de servirse de los indios de forma privada. Y planteaban su derecho de retornar a España. Todo el andamiaje del virreinato era cuestionado.

Ante la imposibilidad de derrotar a los roldanistas y la eventual degradación ulterior de la confrontación, Colón optó por negociaciones, que culminaron con el pacto en Azua en mayo de 1499. Conforme a ese documento, Colón tuvo que dar un paso crucial en dirección opuesta al monopolio de la sociedad mercantil, que consistía en la permisión de que determinados españoles explotasen de forma privada a tribus indígenas. ${ }^{15}$ Se trató de los primeros "repartimientos"; éstos contenían cláusulas que garantizaban la preeminencia de Colón, así como su potestad de designar los beneficiarios de dichos repartimientos. Asimismo, el monto del impuesto a ser devengado por la sociedad mercantil fue establecido en la mitad del oro extraído, proporción muy elevada.

Colón además obtuvo la escisión de los descontentos fundamentada en el hecho de favorecer a algunos, particularmente al mismo Roldán y a algunos de sus seguidores cercanos. Quedaba sobreentendido que el procedimiento tributario continuaría aplicándose y que Colón sería beneficiario básico del conjunto de la empresa. El alcalde mayor fue restituido en sus funciones y pasó a ser uno de los mayores beneficiarios de los repartimientos. Esto le permitió a Colón mantener el estilo autocrático de mando. Los nuevos conatos de inconformidad y rebelión siguieron siendo tratados de manera dura, incluyendo ejecuciones y castigos terribles. Como las fuentes

14 Real cédula dada en Burgos, 23 de abril de 1497. A.G.I., 11, 3, 68v.

15 De las Casas: Historia de las Indias, tomo II, pág. 96. 
de los conflictos no se solucionaban, la situación volvió a tintes sombríos. Todo presagiaba una amplia rebelión. Definitivamente, la autoridad del virrey-almirante resultaba incompatible con el despliegue del interés privado de los españoles residentes. Del mismo dependía a la vez el establecimiento de un esquema de colonización que asentase el poder metropolitano, objetivo de principio que fue tomando contornos cada vez más patentes en los círculos cortesanos. Colón terminó siendo visto en la corte como un obstáculo insuperable para que el incipiente establecimiento diese lugar a una corriente de colonización sobre la cual se consolidase.

La base sobre la que se sustentaron los monarcas para deponer a Colón fue la esclavización de centenares de indígenas desde el interinato de su hermano Bartolomé y haberlos enviado a España. El fracaso de la minería había llevado a Colón a exacerbar los mecanismos de esclavización. Los monarcas lo habían aceptado, aparentemente con dudas, sobre la base del argumento de la "justa guerra", como medio eventual de recabar recursos de la sociedad que redundasen en el reforzamiento estratégico del absolutismo. Pero, a la larga, comprendían que la esclavización se contraponía al interés estratégico del absolutismo, convenientemente sustentado en la explotación tributaria y no en la esclavización. La estrechez de miras de Colón entraba en conflicto irremediable con los requerimientos de una colonización de las nuevas tierras, que incluían una política consistente respecto a las poblaciones aborígenes. Las dudas de los monarcas terminaron expresadas en la recusación del envío de indígenas esclavizados que habían sido entregados en propiedad a algunos roldanistas como secuela del pacto de Azua.

Un tema adicional no menos importante para la reina Isabel tuvo también que ver con la cuestión de la esclavización. Se trataba de la cuestión de la evangelización de los indios, cuyo encargo se hizo con cierta amplitud en las instrucciones del segundo viaje. ${ }^{16}$ Los conflictos que dieron lugar a la huida del padre Buil y la esclavización de los indígenas constituyeron factores que impidieron la conversión de los indígenas. La justificación de la expansión de la soberanía castellana se podía poner en entredicho. Más grave todavía era que se vulneraba la conveniencia para la Corona de que la población aborigen constituyera el fundamento del establecimiento en

16 "Por ende Sus Altezas, deseando que nuestra santa fe católica sea aumentada e acrecentada, mandan e encargan al dicho almirante, virrey e gobernador, que por todas las vías e maneras que pudiere procure e trabaje [en] atraer a los moradores de las dichas islas e tierra firme a que se conviertan a nuestra santa fe católica" 
América. Una de las tantas novedades que se encuentran en el reciente libro de Consuelo Varela es la oposición de Colón a la evangelización, amparado en el pretexto de que primero debían aprender el idioma castellano. En 1494 Colón había enviado a fray Ramón Pané, un fraile ermitaño catalán, a que viviera entre tribus macorixes, a fin de que conociera el idioma y los usos culturales autóctonos. ${ }^{17}$ De acuerdo a Arrom, Pané debió entregar su manuscrito a Colón en 1498. El testimonio del ermitaño se volvió contra el almirante. ${ }^{18}$ Pané estuvo acompañado de otros dos frailes franciscanos, los cuales regresaron a España en 1496. Estos denunciaron el obstáculo a la evangelización que representaba el gobierno colombino. Regresaron a la isla en compañía del nuevo gobernador Bobadilla y desde los primeros días de su estadía, dijeron haber reanudado la labor evangelizadora atrayendo a la fe a gran número de adeptos.

Aun en ese momento de redefinición que implicó la destitución de Colón, la Corona no renunciaba a sus prerrogativas monopólicas sobre el oro y demás artículos de gran valor. Con la designación de Francisco de Bobadilla como gobernador, en 1500, quedaba desconocida la autoridad de Colón, al igual que los contornos institucionales del virreinato que le daban sustancia legal. Pero, paralelamente, los reyes se propusieron compaginar la coexistencia del reconocimiento del interés privado que previniese nuevos conflictos con el mantenimiento de rasgos tributarios, particularmente la libertad genérica de los indígenas, y ámbitos del monopolio sobre el comercio y la extracción de oro. Esta solución se revelaría no menos problemática que el diseño de sociedad y autoridad implantado por el almirante.

17 El fraile "vivió primero en la provincia de Macorís, donde se hablaba una lengua distinta a la general. En la primavera de 1495 pasó al cacicazgo de Guarionex, acompañado de un fiel neófito que sabía ambas lenguas y le sirvió de traductor y maestro.” Arrom, José Juan: Imaginación del Nuevo Mundo. Diez estudios sobre los inicios de la narrativa hispanoamericana, Siglo XXI, México, 1991, pág. 37.

18 Escribe fray Ramón Pané: "Nosotros estuvimos por consiguiente con aquel cacique Guarionex casi dos años, enseñándole siempre nuestra santa fe y las costumbres de los cristianos. Al principio mostró buena voluntad y dio esperanza de hacer cuanto nosotros quisiésemos y de querer ser cristiano (...). Pero después se enojó y abandonó su buen propósito, por culpa de otros principales de aquella tierra, los cuales le reprendían porque deseaba obedecer la ley de los cristianos, siendo así que los cristianos eran malvados y se habían apoderado de sus tierras por la fuerza”. Fray Ramón Pané: Relación acerca de las antigüedades de los indios, Estudio preliminar y notas de José Juan Arrom, Siglo XXI, México, 1974, pág. 48. 